\title{
Effects of olmesartan on arterial stiffness in rats with chronic renal failure
}

\author{
Yao-Chen Chuang ${ }^{*}$, Ming-Shiou $\mathrm{Wu}^{2}$, Yi-Kai Su² and Kwang-Ming Fang ${ }^{3}$
}

\begin{abstract}
Background: It has been suggested that the antioxidant properties of olmesartan (OLM), an angiotensin II type 1 receptor $\left(A T_{1} \mathrm{R}\right)$ blocker, contribute to renal protection rather than blood pressure lowering effects despite the fact that causal relationships between hypertension and renal artery disease exist. This study aimed to examine the hypothesis whether the antioxidative activities of OLM were correlated to arterial stiffness, reactive oxygen species and advanced glycation end products (AGEs) formation in rats with chronic renal failure (CRF).

Methods: CRF rats were induced by 5/6 nephrectomy and randomly assigned to an OLM (10 mg/day) group or a control group. Hemodynamic states, oxidative stress, renal function and AGEs were measured after 8 weeks of OLM treatment.

Results: All the hemodynamic derangements associated with renal and cardiovascular dysfunctions were abrogated in CRF rats receiving OLM. Decreased cardiac output was normalized compared to control $(p<0.05)$. Mean aortic pressure, total peripheral resistance and left ventricular weight/body weight ratio were reduced by $21.6 \%(p<0.05), 28.2 \%(p<0.05)$ and 27.2\% ( $(p<0.05)$. OLM also showed beneficial effects on the oscillatory components of the ventricular after-load, including 39\% reduction in aortic characteristic impedance $(p<0.05)$, $75.3 \%$ increase in aortic compliance $(p<0.05)$ and $50.3 \%$ increase in wave transit time $(p<0.05)$. These results implied that OLM attenuated the increased systolic load of the left ventricle and prevented cardiac hypertrophy in CRF rats. Improved renal function was also reflected by increases in the clearances of BUN (28.7\%) and serum creatinine (SCr, 38.8\%). In addition to these functional improvements, OLM specifically reduced the levels of malondialdehyde (MDA) equivalents in aorta and serum by $14.3 \%$ and $25.1 \%$, as well as the amount of AGEs in the aortic wall by $32 \%(p<0.05)$ of CRF rats.
\end{abstract}

Conclusion: OLM treatment could ameliorate arterial stiffness in CRF rats with concomitant inhibition of MDA and AGEs levels through the reduction of oxidative stress in aortic wall.

Keywords: Advanced glycation end products, Aortic impedance analysis, Chronic renal failure, Diabetes

\section{Background}

Increased arterial stiffness is associated with the development and progression of chronic kidney disease (CKD) [1,2]. The accumulation of advanced glycation end products (AGEs) due to reduced capability of detoxification and excretion in CKD patients has been confirmed to worsen vascularpathy [3,4]. AGEs stiffen collagen backbones [5], promote collagen deposition in heart and aorta [6], increase the expression of growth factors and cytokines [7] and induce inflammation [8].

\footnotetext{
* Correspondence: d93441002@ntu.edu.tw

'Institute of Physiology, College of Medicine, National Taiwan University, 10 F,

No. 1, Sec., 1, Jen-Ai Road, Zhongzheng Dist., Taipei City 100, Taiwan

Full list of author information is available at the end of the article
}

These products can consequently lead to glomerular and tubulointerstitial injury. Satisfactory glycermic control, which can reduce AGE accumulation, has been shown effective on lowering arterial stiffness in diabetic patents [9]. Angiotensin receptor blockers (ARBs) exhibit pleiotropic effects that prevent vascular stiffness [10-12]. Previous studies have demonstrated that ARBs have renoprotective effects to reduce diabetic nephropathy and complications, such as hyperfiltration, increased intraglomercular pressure and urinary protein excretion, in patients with or without diabetes [13,14]. ARBs reduced AGE formation by blocking excess oxidative stress has been verified in vitro [7]; however, the 
protective effect of ARBs on AGE formation remained controversial in clinical study [15].

The effects of Olmesartan (OLM), a newest ARB, on oxidative stress have been confirmed in a clinical study of patients with diabetes [16]. Although it was suggested that the antioxidant properties of OLM contribute to renal protection rather than $\mathrm{BP}$ lowering effects [17], the causal relationships between hypertension and renal disease exist $[18,19]$. A recent report indicated that OLM decreased the time to the onset of microalbuminuria in patients with type 2 diabetes [20]. Therefore, this study aimed to examine the hypothesis whether the antioxidative activities of OLM were correlated to arterial stiffness, reactive oxygen species (ROS) and AGEs formation by using 5/6 nephrectomy-induced CRF rats. Besides, we also evaluated the effect of OLM on the renal function by the measurements of serum creatinine $(\mathrm{SCr})$ and blood urea nitrogen (BUN).

\section{Methods}

\section{Experimental Animals}

Male Wistar rats (8 weeks old) were randomly divided into three groups; (1) normal controls (NC), (2) CRF, and (3) CRF treated with OLM (CRF + OLM). All rats were allowed free access to water and chow (Rodent Diet 5001, PMI Lab, St. Louis, MO, USA) and housed in an animal room with a 12-h light/dark cycle. All animal experiments were conducted in accordance with the Guide for the Care and Use of Laboratory Animals and the protocols were approved by the Animal Care and Use Committee of the National Taiwan University. The rats were allocated randomly to 3 groups of 15 each: (1) normal control (NC), (2) chronic renal failure (CRF), and (3) OLM-treated CRF rats (OLM + CRF).

\section{5/6 Subtotal Nephrectomy}

Rat 5/6 subtotal nephrectomy ( $\mathrm{SNx}$ ) is a classic animal model of CRF with enhanced activity of the reninangiotensin system. In this study, CRF was induced by 5/6 subtotal nephrectomy as previously described [21]. Under anesthesia with sodium pentobarbital $(50 \mathrm{mg} / \mathrm{kg}$; i.p.), two branches of the left renal artery were ligated to create an infarction after right nephrectomy. Rats in the normal control group underwent sham surgeries. After recovering for one week, CRF rats received daily oral gavage with OLM $(10 \mathrm{mg} / \mathrm{kg} /$ day $)$ or placebo for the next 8 weeks.

\section{Aortic input impedance spectra}

General surgical procedures and measurements of hemodynamic variables in anesthetized rats were described before [22]. Briefly, after anesthesia and intubation, the rats were placed on a heating pad and ventilated with a rodent respirator (Model 131; New England
Medical Instruments, Medway, MA). The chest wall was opened through the right second intercostal space. An electromagnetic flow probe (Model 100 series, internal circumference $=8 \mathrm{~mm}$; Carolina Medical Electronics, King, NC) was positioned around the ascending aorta to measure the pulsatile aortic flow. A high fidelity pressure catheter (Model SPC 320, size=2 F; Millar Instruments, Houston, TX) was used to measure the pulsatile aortic pressure via the isolated carotid artery on the right side. An electrocardiogram from lead II was recorded with a Gould Electrocardiograph/Biotech amplifier (Gould Electronics, Cleveland, $\mathrm{OH}$ ).

The selected pressure and flow signals of 5-10 beats were averaged in the time domain using the peak $\mathrm{R}$ wave of the electrocardiogram as the fiducial point. Because of the spatial distance between the flow probe and proximal aortic pressure transducer, timing between the pressure and flow signals was corrected by a timedomain approach, in which the foot of the pressure waveform was realigned with that of the flow [23]. The resulting pressure and flow signals were subjected to further vascular impedance analysis.

The aortic input impedance was obtained from the ratio of the ascending aortic pressure harmonics to the corresponding flow harmonics, using a standard Fourier series expansion technique [22,24,25]. Total peripheral resistance of the systemic circulation was calculated as the mean aortic pressure divided by the mean aortic flow rate. The aortic characteristic impedance was computed by averaging the high-frequency moduli of the aortic input-impedance data points $\left(4^{\text {th }}-10^{\text {th }}\right.$ harmonics $)$ [26,27].

After taking the aortic characteristic impedance into consideration, we calculated the systemic arterial compliance $(C)$ at the mean aortic pressure $\left(P_{m}\right)$ by expanding the two-element Windkessel model into a three-element model [28], which accounted for the nonlinear exponential pressure-volume relationship:

$$
C\left(P_{m}\right)=\frac{S V b}{K+Z_{C} S V / A d} \times \frac{e^{b \times P_{m}}}{e^{b \times P_{i}}-e^{b \times P_{d}}},
$$

where $S V$ is the stroke volume, $K$ is the ratio of total area under the aortic pressure curve to the diastolic area $(A d)$, $Z_{c}$ is the aortic characteristic impedance, $b$ is the coefficient in the pressure-volume relationship $(-0.0131 \pm 0.009$ in the aortic arch), $P_{i}$ is the pressure at the time of incisura, and $P_{d}$ is the end-diastolic pressure.

The wave transit time can be computed by the impulse response of the filtered aortic input impedance. This was achieved using an inverse transformation of aortic input impedance after multiplying the first 12 harmonics by a Dolph-Chebychev weighting function of the $24^{\text {th }}$ order [29]. Then, the time-domain reflection factor was 
derived as the amplitude ratio of the backward-toforward peak pressure wave using the method proposed by Westerhof et al. [30]. Thus, both the wave transit time and the wave reflection factor characterized wave reflection phenomena in the vasculature.

\section{Biochemical analysis}

After 8 weeks, 15 rats from each group were catheterized under anesthesia for measurements of vital signs. Blood samples were collected directly via heart puncture and serum was obtained by centrifugation and then refrigerated until analysis. Rats were then thoroughly perfused with iced phosphate buffered saline. Aorta and heart samples were collected after scarification. Heart samples were weighed and then cut into pieces either for fixation in formalin or storage at $-80^{\circ} \mathrm{C}$. The levels of $\mathrm{SCr}$ and BUN were measured with an autoanalyser (Hitachi Model 7070, Hitachi Electronics Co., Ltd., Tokyo, Japan).

\section{Immunohistochemical analysis}

Aortic sections with thickness of $4 \mu \mathrm{m}$ were used for AGE staining. Briefly, tissue sections were deparaffinized and hydrated through a series in xylene and graded alcohol $(100 \%, 90 \%, 70 \%$, and $50 \%)$. Sections were then treated with $3 \% \mathrm{H}_{2} \mathrm{O}_{2} /$ methanol and incubated in normal horse serum (3\%) for $20 \mathrm{~min}$ at room temperature, followed by incubation with anti-AGE monoclonal antibody 6D12 (Trans Genic Inc., Kumamoto, Japan) (1:50 dilution) for $30 \mathrm{~min}$ at room temperature. After washing 3 times with PBS, diluted biotinylated "universal" secondary antibody (R.T.U. Vectastain Universal Elite ABC kit, Vector Laboratories Inc., Burlingame, CA) was added and incubated for another $30 \mathrm{~min}$ at room temperature. The density was detected using avidinbiotin-peroxidase (R.T.U. Vectastain Universal Elite $\mathrm{ABC}$ kit, Vector Laboratories Inc., Burlingame, $\mathrm{CA}$ ) and diaminobenzidine (ImmPACT DAB Perxoidase Substrate, Vector Laboratories Inc., Burlingame, CA) as substrate; the sections were then counterstained with hematoxylin.

\section{Western blot analysis}

The method used to determine collagen glycation in the aortic wall was previously described by Turk et al [31]. After extensive digestion with pepsin, proteinase $\mathrm{K}$, and collagenase, the extracts from aortic walls were subjected to a $12 \%$ sodium dodecyl sulfate-polyacrylamide gel electrophoresis (SDS-PAGE) using a Mini PROTEANs 3 System (Bio-Rad Lab, Hercules, CA, USA). Each sample contained $40 \mu \mathrm{g} / \mu \mathrm{l}$ of protein. The gels were transferred to polyvinylidene difluoride membranes and then incubated with an anti-AGE monoclonal antibody 6D12 (1: 2500 dilution) for $60 \mathrm{~min}$ at room temperature, followed by using a chemiluminescence method to determine densitometry using a DolphinChemi mini System (Wealtec Corp., Sparks, Nevada, USA).

\section{MDA measurement}

The levels of MDA equivalents were determined by thiobarbituric acid reactive substances (TBARS) assay kit (Cayman Chemical Company, Ann Arbor, Michigan, USA). Briefly, samples of an aorta or left ventricle were homogenized in RIPA buffer (Sigma Chemical Co, St. Louis, MO, USA) with a $1 \%$ protease inhibitor cocktail (Sigma Chemical Co, St. Louis, MO, USA). After a brief centrifugation at $1600 \times \mathrm{g}$ for $10 \mathrm{~min}$ at $4^{\circ} \mathrm{C}$, the supernatants were obtained for measuring absorbance at $540 \mathrm{~nm}$.

\section{Statistical analyses}

Results are given as means \pm standard errors (SD). Twoway analysis of variance (ANOVA) was used to determine the effects of CRF and OLM on the physical properties of the rat arterial system. Simple effects analysis was used when significant interactions between CRF and OLM were found. Comparisons among means within factor levels used Tukey's honestly significant difference method. $P<0.05$ was considered to be significant.

\section{Results}

In comparison with the normal control, the CRF rats yielded significant changes in renal function, arterial pressure and left ventricular hypertrophy. Apart from significantly lowering blood pressure, all the above abnormalities in CRF rats were effectively ameliorated after 8 weeks of OLM treatment (Table 1).

Table 1 Comparisons of body weight, renal function, blood pressure and left ventricular weight in the Wistar rat 8 weeks after subtotal nephrectomy (SNx)

\begin{tabular}{|c|c|c|c|}
\hline & NC $(n=13)$ & CRF $(n=14)$ & CRF + OLM $(n=14)$ \\
\hline & $\overline{\text { mean } \pm \mathrm{SE}}$ & mean $\pm \mathrm{SE}$ & mean $\pm S E$ \\
\hline BW (g) & $480 \pm 11.9$ & $412.1 \pm 16.6^{*}$ & $443.6 \pm 10.5$ \\
\hline BUN (mg/dl) & $19.35 \pm 0.8$ & $64.76 \pm 3.35^{*}$ & $46.79 \pm 2.72^{\dagger}$ \\
\hline $\mathrm{SCr}(\mathrm{mg} / \mathrm{dl})$ & $0.66 \pm 0.02$ & $1.7 \pm 0.1^{*}$ & $1.04 \pm 0.09^{\dagger}$ \\
\hline$P_{s}(\mathrm{~mm} \mathrm{Hg})$ & $117.2 \pm 2.2$ & $178.5 \pm 8.6^{*}$ & $135.7 \pm 6.2^{\dagger}$ \\
\hline$P_{d}(\mathrm{~mm} \mathrm{Hg})$ & $94.2 \pm 2.3$ & $126.9 \pm 5.2^{*}$ & $101.8 \pm 6.1^{\dagger}$ \\
\hline$P_{m}(\mathrm{~mm} \mathrm{Hg})$ & $106.7 \pm 2.3$ & $152.1 \pm 6.4^{*}$ & $119.2 \pm 6.1^{\dagger}$ \\
\hline$P P(\mathrm{~mm} \mathrm{Hg})$ & $23.0 \pm 0.6$ & $51.6 \pm 4.4^{*}$ & $33.8 \pm 2.2^{\dagger}$ \\
\hline LWW (g) & $0.98 \pm 0.03$ & $1.20 \pm 0.04^{*}$ & $0.94 \pm 0.05^{\dagger}$ \\
\hline LWW/BW (\%o) & $2.04 \pm 0.05$ & $2.9 \pm 0.11^{*}$ & $2.11 \pm 0.08^{\dagger}$ \\
\hline
\end{tabular}

NC, normal controls; CRF, chronic renal failure; OLM, olmesartan. Abbreviations: $B W$, body weight; $P_{s}$, aortic systolic pressure; $P_{d}$, aortic diastolic pressure; $P_{m}$, mean aortic pressure; $P P$, pulse pressure; $L V W$, left ventricular weight. ${ }^{*}: P<0.05, \mathrm{CRF}$ vs. NC; $\dagger: P<0.05, \mathrm{CRF}+\mathrm{OLM}$ vs. CRF. 
In comparison with normal controls, CRF rats showed significantly affected hemodynamics characterized by decreased heart rate $(396.26 \pm 10.76$ vs. $364.30 \pm 10.02$ beats $/ \mathrm{min}, p<0.05)$ and cardiac output $(2.30 \pm 0.09$ vs. $2.07 \pm 0.09 \mathrm{ml} / \mathrm{sec}, p<0.05$ ) (Figure $1 \mathrm{~A}, \mathrm{~B}$ ), and conversely, a marked increase in total peripheral resistance $(p<0.05)$ (Figure 1D). The decrease in cardiac output coupled with the increase in mean aortic pressure in CRF rats (Table 1 ) caused a marked rise in total peripheral resistance. After 8 weeks of OLM treatment, CRF rats were normalized as evidenced by increased cardiac output $(2.07 \pm 0.09$ vs. $2.28 \pm 0.09 \mathrm{ml} / \mathrm{sec}, p<0.05)$ and decreased total peripheral resistance $(74.56 \pm 3.43$ vs. $53.52 \pm 3.77, \mathrm{mmHg} \mathrm{sec} / \mathrm{mL}, p<0.05$ ) (Figure 1B, D).

Figure 2 depicts the aortic characteristic impedance [32] and wave reflection factor $\left(R_{f}\right)$ from the CRF rats were significantly increased than that from the controls $(0.54 \pm 0.03$ vs. $0.76 \pm 0.03 \mathrm{mmHg}$ sec/ $\mathrm{mL}, p<0.05)$ (Figure 2A, C). These changes were accompanied by the decreases of aortic compliance $\left(C_{m}\right)(13.50 \pm 0.60$ vs. $5.03 \pm 0.46, p<0.05$, Figure $2 C$ ) and wave transit time $(\tau)$
$(27.62 \pm 1.02$ vs. $16.26 \pm 0.59 \mathrm{~ms}, p<0.05$, Figure 2D). Treatment with OLM showed significant effects on retarding the CRF-induced mechanical alterations in the Windkessel vessels (Table 1), as manifested by the $39 \%$ reduction in aortic characteristic impedance $\left(Z_{\mathcal{O}}\right.$ $2.23 \pm 0.21$ vs. $1.36 \pm 0.08, p<0.05)$ and the $75.3 \%$ increase in aortic compliance $\left(C_{m}, 5.03 \pm 0.46\right.$ vs. $8.82 \pm 0.92, p<0.05)$. Early return with the augmented magnitude of the reflected wave from the peripheral circulation in CRF rats was impeded following OLM treatment, as demonstrated by the increase of $50.3 \%$ in wave transit time ( $\tau, 16.26 \pm 0.59$ vs. $24.44 \pm 1.76, p<0.05)$.

There were significant changes in renal function as shown by the differences in clearances of BUN and $\mathrm{SCr}$ between normal rats and CRF rats (Table 1). At week 8 after the induction of CRF, the BUN was 3.3-fold and $\mathrm{SCr}$ 2.6-fold higher in CRF rats than the controls $(p<0.05)$, indicating an impaired renal function. We observed significant increases in the clearances of both BUN and SCr in the CRF rats following OLM administration, of which BUN decreased by $28.7 \%(p<0.05)$ and
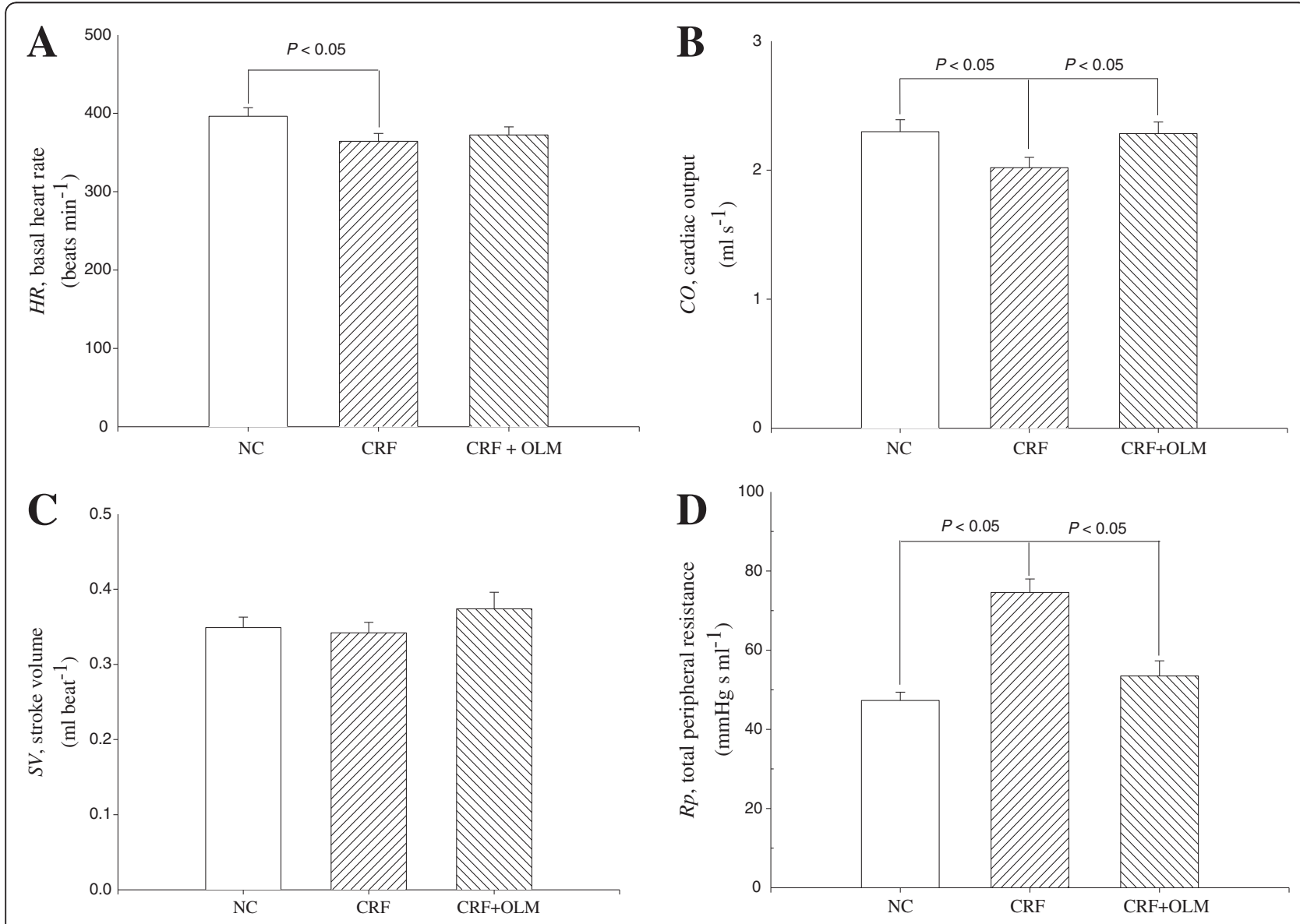

Figure 1 Effects of OLM treatment on induced CRF rats and comparisons among different groups ( $\mathrm{n}=14$ in each group). HR, heart rate $(\mathbf{A})$; CO, cardiac output (B); SV, stroke volume $(\mathbf{C})$; $\mathrm{R}_{\mathrm{p}}$, total peripheral resistance (D); NC, normal controls; CRF, chronic renal failure; OLM, olmesartan. 

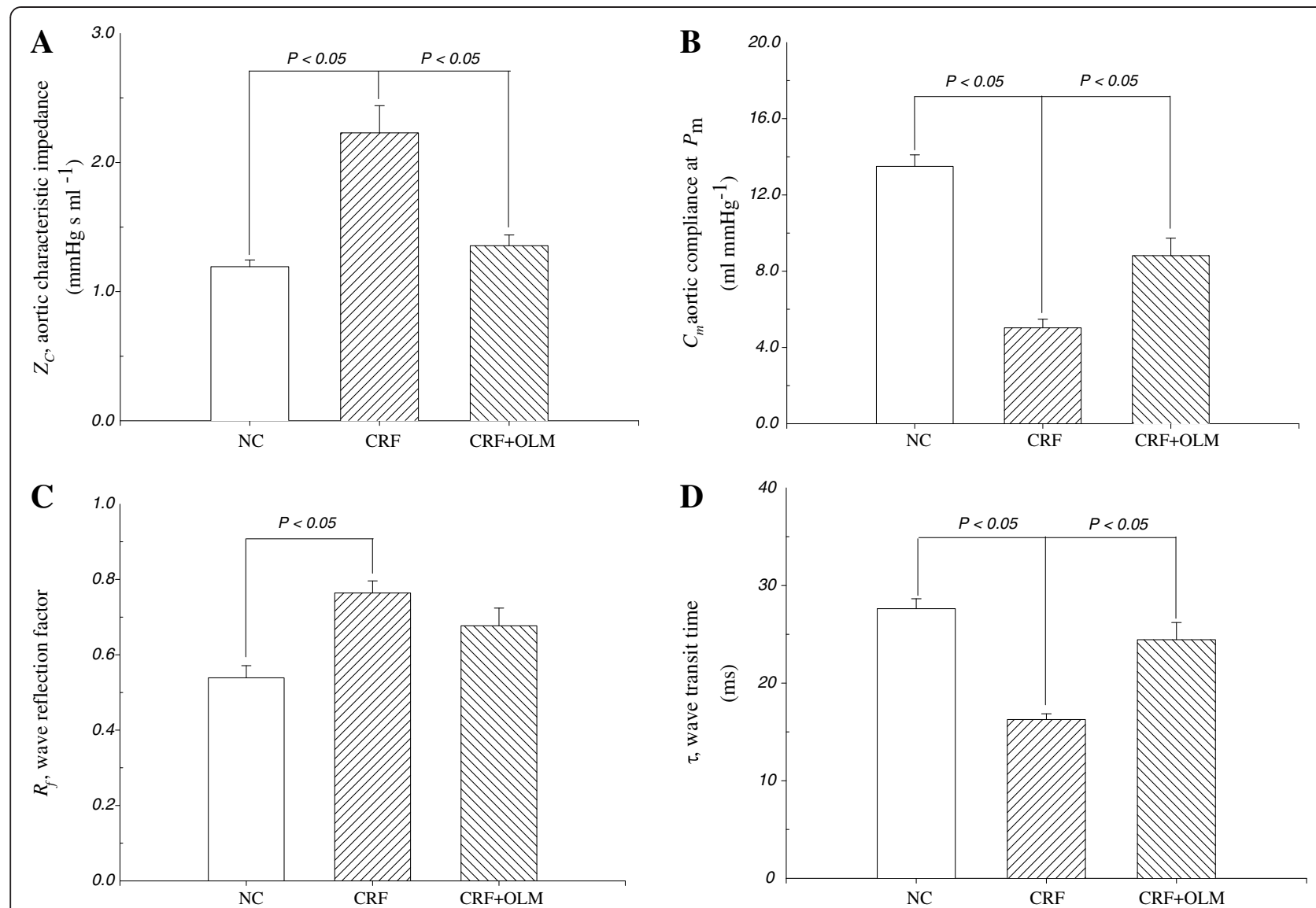

Figure 2 Effects of OLM treatment on induced CRF rats and comparisons among different groups ( $\mathrm{n}=14$ in each group). $Z_{C}$, aortic characteristic impedance $(\mathbf{A})$; $C_{m}$, systemic arterial compliance $(\mathbf{B}) ; R_{f}$, wave reflection factor $(\mathbf{C})$; $\tau$, wave transit time $(\mathbf{D})$; $N C$, normal controls; $C R F$, chronic renal failure; OLM, olmesartan.

SCr 38.8\% $(P<0.05)$ when compared to those without treatment.

The immunointensity indicating AGE accumulation was higher in the media aortic wall of CRF rats (Figure 3), which was significantly reduced following OLM treatment for 8 weeks. Consequently, the amount of AGEs was $142 \%$ increased in collagen samples from CRF rats compared with control samples, displaying a molecular weight fragments between 26 and $34 \mathrm{KDa}$ (Figure 4). After treatment with OLM for 8 weeks, AGEs decreased by $32 \%$ in glycation-derived modification of aortic collagen $(p<0.05)$.

MDA is a biomarker of lipid-related oxidative stress, which indicates the degree of lipid peroxidation. The levels of MDA equivalents of the aorta and serum in CRF rats were markedly increased than that of controls, ranging from $1.50 \pm 0.05$ to $2.02 \pm 0.04 \mathrm{nmol} \mathrm{mg}^{-1}$ protein $(p<0.05)$ in aorta and from $12.67 \pm 1.13$ to $17.01 \pm 0.78 \mathrm{mM}(p<0.05)$ in serum (Figure 5). OLM treatment prevented CRF-induced oxidative stress in both aorta and serum, as evidenced by the reductions of levels of MDA equivalents by $14.3 \%$ and $25.1 \%$, respectively.

\section{Discussion}

OLM is an ARB that is characterized by potent blood pressure-lowering efficacy with a fast onset, prolonged duration of action and good tolerability. Some clinical studies have demonstrated that OLM has renoprotectve function in patients with type 2 diabetes, and beneficial effects to reduce cardiovascular risk in patients with atherosclerosis [20,33]. Recent studies have also reported that OLM is associated with a beneficial effect on lipid metabolism [34], reduction of proteinuria [35], and protection of endothelial cell from the injuries induced by oxidized LDL [36]. Our results added to the evidence that OLM exerts beneficial influences on cardiovascular disease and diabetes.

\section{Impacts of OLM on cardiovascular functional parameters} All the arterial pressures, including aortic systolic blood pressure, aortic diastolic pressure and mean aortic 


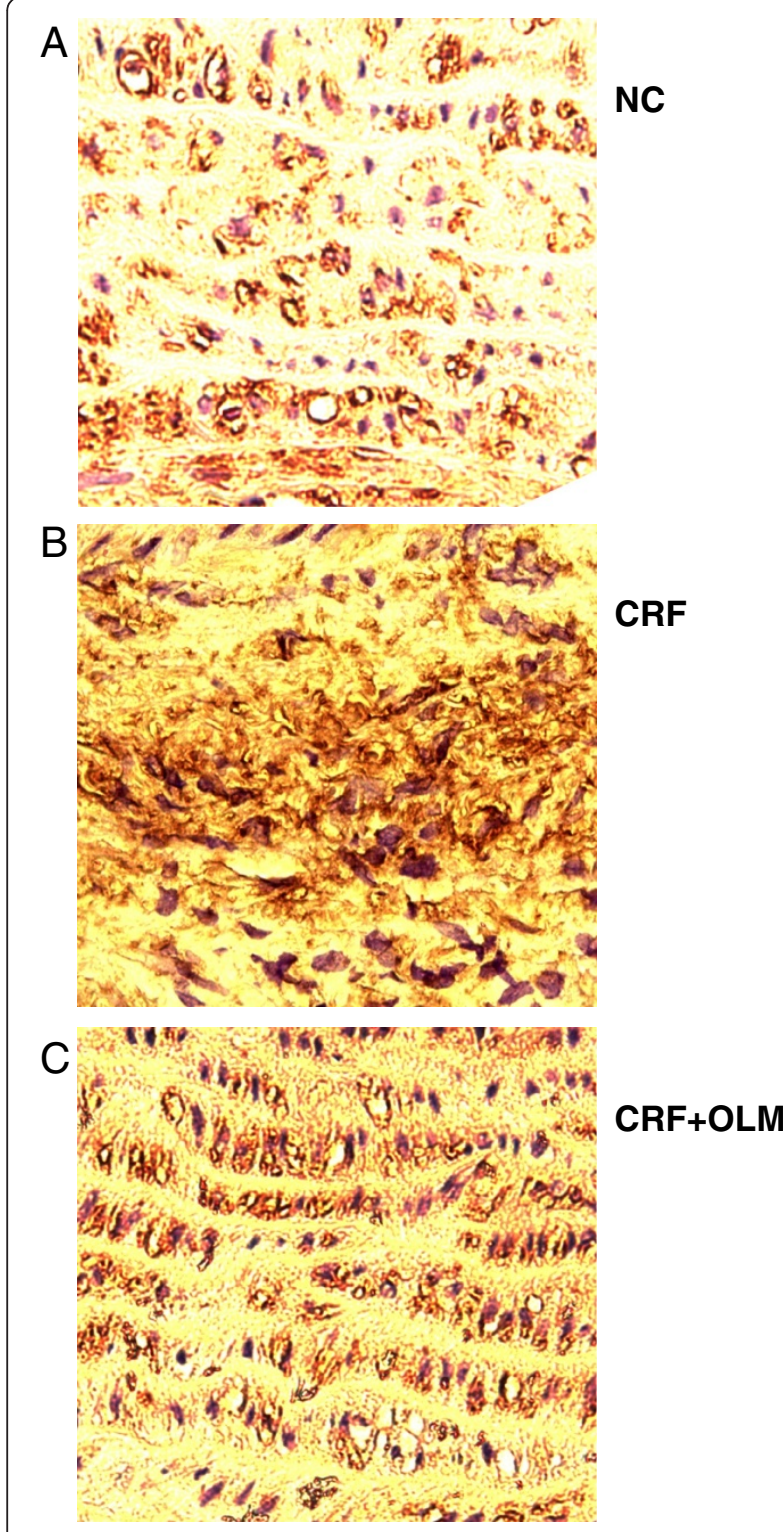

Figure 3 Immunohistochemical staining for advanced glycation end products (AGEs) in the aortas at 8 weeks after SNx. NC, normal controls; CRF, chronic renal failure; OLM, olmesartan. Magnification 400x.

pressure, significantly increased in CRF rats (Table 1). Our data demonstrated that OLM showed significant effects on lowering these increased pressures. The pressure-lowering effect of OLM was partly due to its antagonistic actions on Angiotensin-II type 1 receptor $\left(\mathrm{AT}_{1} \mathrm{R}\right)$, which consequently inhibit vasoconstriction and ameliorate hypertension [37].

A decline in cardiac output and an increase in mean aortic pressure were associated with increased total peripheral resistance in CRF rats (Figure 1D). The increase in total peripheral resistance could have largely resulted from vasoconstriction and arterial stiffening. In CRF rats, ROS production via $\mathrm{AT}_{1} \mathrm{R}$-mediated NADPH oxidase activation and the reaction of superoxide [38], one of the ROS, with nitric oxide (NO) generates peroxynitrite $\left(\mathrm{ONOO}^{-}\right)$and diminishes the vascular relaxation activity of NO [39]. Apart from activating RAS, previous studies have demonstrated that accumulated AGEs reduced NO levels, caused increased vascular smooth muscle tone [40], contributed to the cross-linking of glycated collagen in the arterial walls of CRF rats [41] and consequently led to increased arterial stiffness and total peripheral resistance. The CRF-derived physical changes in vessel resistance were ameliorated by OLM treatment, as shown by a significant reduction (28.3\%) in total peripheral resistance. We therefore hypothesized that OLM treatment would improve CRF-induced vasodilatory dysfunction by blocking the action of Angiotensin II and reducing AGE formation.

Aortic characteristic impedance is frequently used as an indicator of aortic stiffness. Higher aortic characteristic impedance is associated with a stiffer aortic wall [40]. When compared to normal control rats, the aortic characteristic impedance increased $\left(Z_{c}\right.$ in Figure $\left.2 \mathrm{~A}\right)$ and wave transit time decreased ( $\tau$ in Figure 2D) in CRF rats. Because the CRF-derived change in wave transit time could be a consequence of a change in pulse wave velocity [40], our results suggested that a decline in aortic distensibility had occurred in CRF rats.

The material properties of distensibility and compliance (together known as the elastic modulus) are used to describe the stiffness of a hollow vessel. Stroke volume and aortic compliance can also affect the magnitude of the pulse pressure. The arterial pulse pressure varies directly with the stroke volume, but varies inversely with the arterial compliance [40]. Our results showed increased arterial pulse pressure in CRF rats (Table 1), no significant change in stroke volume (Figure 1C) and decreased aortic compliance (Figure 2B), which suggest that the elevated arterial pulse pressure was associated with the reductions in compliance and distensibility and the aortic wall had stiffened. Decreased aortic distensibility in rats with CRF was prevented by OLM administration, as indicated by a $39 \%$ reduction in aortic characteristic impedance and a $50.3 \%$ increase in wave transit time. OLM treatment also increased the systemic arterial compliance in CRF rats by $25.3 \%$. The improvement of the CRF-derived arterial stiffness implicated that OLM may reduce the formation of glycated collagen in the aortic wall.

Changes in timing or magnitude of the pulse wave reflection impair the loading condition of the left ventricle coupled to its arterial system [40]. Our findings of increased wave reflection factor (Figure $2 \mathrm{C}$ ) and shortened wave transit time (Figure 2D) indicated that CRF 


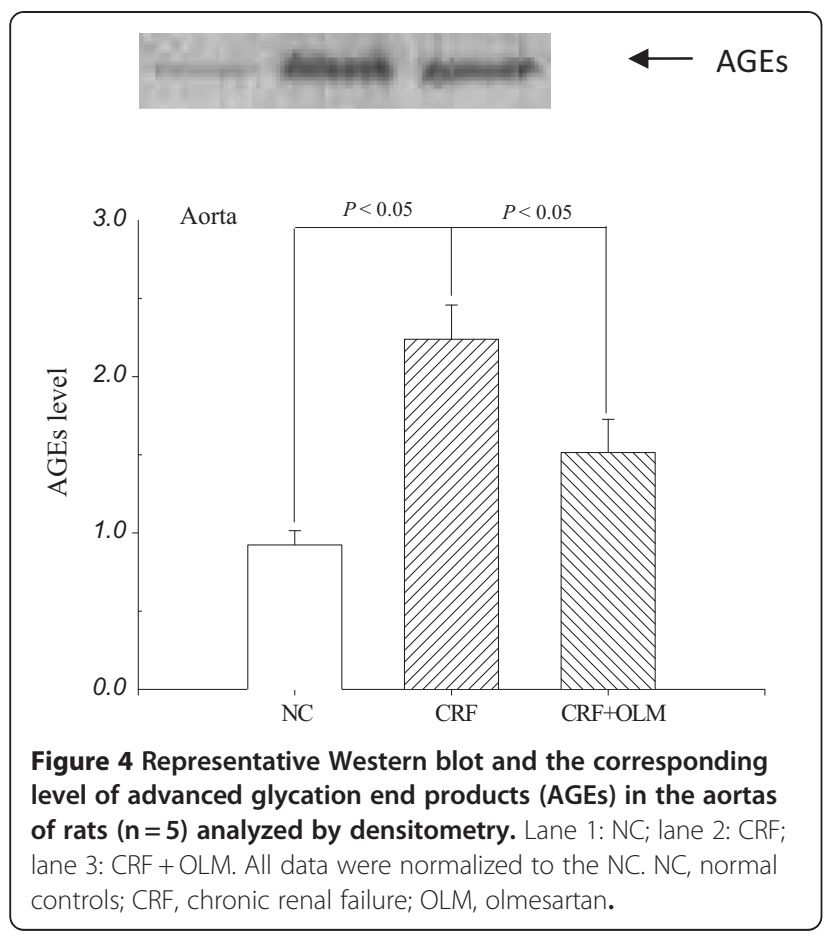

changed the timing and magnitude of the pulse wave reflection to augment the systolic load of the left ventricle. The impaired systolic loading condition of the left ventricle caused the heart to adapt by muscular hypertrophy (Table 1). Furthermore, the increase in wave transit time indicated that OLM prevented AGE accumulation in the arterial wall collagen of CRF rats. OLM also improved the systolic loading condition of the left ventricle coupled to its vasculature system. The decreased ratio of the left ventricular weight to body weight also suggests that OLM treatment decreased vascular load and prevented CRF-related cardiac hypertrophy.
Effects of OLM treatment on the levels of AGE and MDA A striking increase in the AGE content of aortic collagen in CRF rats was observed in our study, suggesting that AGE-modulated collagen led to aortic stiffness. We also explored the histological evidence of considerable AGEs accumulation increased by $142 \%$ on aortic tissue of CRF rats (Figures $3 \mathrm{C}$ and $5 \mathrm{C}$ ), and it was decreased by $32 \%$ after OLM treatment for 8 weeks (Figures 3D and 5). Our results that AGEs played an important role in vascular dynamics were in agreement with previous studies $[42,43]$.

MDA is frequently measured as an indicator of lipid peroxidation and oxidative stress [44] and increased in patients with CKD [45]. Since oxidative stress was involved in the formation of AGEs [46], it might be possible to attenuate AGE formation by inhibiting several oxidative steps $[11,47]$. Some recent studies have proved that OLM attenuated the level of MDA equivalents and subsequently lessened the formation of AGEs in CRF rats $[3,48,49]$. We verified the MDA-lowering effect according to the levels of MDA equivalents decreased by $14.3 \%$ in the aorta and $25.1 \%$ in the serum after OLM treatment. Both the formation of AGEs and MDA are involved with oxidative processes producing their carbonyls or dicarbonyls. The mechanism by which OLM inhibits AGE formation was suggested to be associated with its potentials to suppress carbonyl/dicarbonyl radicals [11]. Furthermore, a previous report demonstrated that treatment of Nx rats with OLM for 8 weeks significantly reduced superoxide production [39]. Our findings were consistent with these previous studies indicating that the formation of AGEs is related to oxidative stress and might be reduced by the antioxidant ability of OLM. In addition, OLM possess renal protective properties via ameliorating progressive glomerular injury $[39,50]$. The findings of markedly increased excretion of BUN and
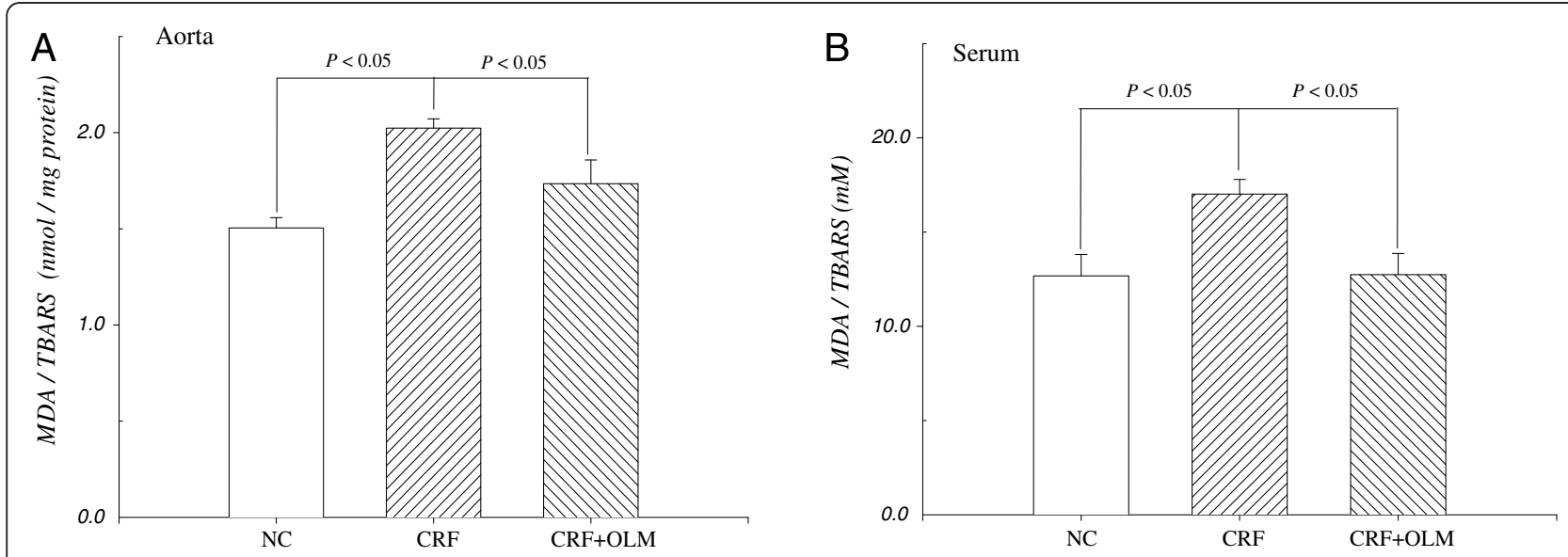

Figure $\mathbf{5}$ The levels of malondialdehyde (MDA) equivalents in the aorta (A) and serum (B) measured by TBARS assay. Increased level of MDA equivalents was observed in rats with CFR, and decreased in CRF rats $(n=12)$ following OLM treatment. 
SCr (Table 1) suggest that the improvement of renal function may lead to reduced AGEs accumulation in the serum of CRF rats.

\section{Conclusion}

Our findings demonstrated that OLM provides significant protection against CRF-derived changes in the mechanical properties of blood vessels, especially the Windkessel vessels. The underlying mechanism is likely to be involved with the reduction of oxidative stress leading to subsequent decrease in the formation and accumulation of AGEs in arterial wall collagen. Other than the pressure-lowering effect of vasodilation in OLM, the inhibition of AGEs by OLM may be another pathway contributed to the improvement of the CRF-derived deterioration of blood vessels in CRF rats. The results of the current study must be also viewed in the context of many other studies of renal and cardiovascular outcomes that have shown beneficial effects of OLM.

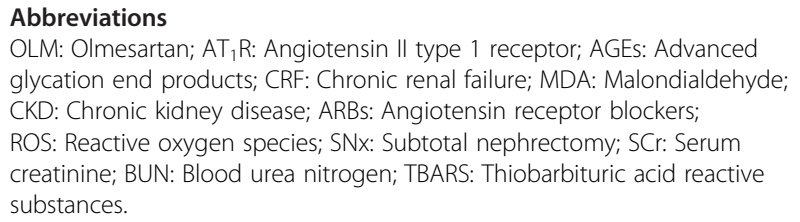

\section{Competing interests}

The authors declare that they have no competing interests.

\section{Authors' contributions}

YCC conceived of the study, performed the experimental procedures, and drafted the manuscript. MSW and YKS provided expertise in diabetes and coordinated the research plan. KMF contributed to discussion and edited the paper. All authors contributed to results interpretation and discussion, as well as approved the final version of the manuscript.

\section{Acknowledgements}

We thank the Third Core Lab of Department of Medical Research in National Taiwan University Hospital for technical assistance.

\section{Author details}

${ }^{1}$ Institute of Physiology, College of Medicine, National Taiwan University, 10 F, No. 1, Sec., 1, Jen-Ai Road, Zhongzheng Dist., Taipei City 100, Taiwan. ${ }^{2}$ Department of Internal Medicine, National Taiwan University Hospital, No.7, Chung Shan S. Rd., Zhongzheng Dist., Taipei City 100, Taiwan. 'Department of Dental Technology and Materials Science, Central Taiwan, University of Science and Technology, No.666, Buzih Road, Beitun District, Taichung City 40601, Taiwan.

Received: 1 June 2012 Accepted: 7 June 2012

Published: 13 June 2012

\section{References}

1. Chue CD, Townend JN, Steeds RP, Ferro CJ: Arterial stiffness in chronic kidney disease: causes and consequences. Postgrad Med J 2010, 86(1019):817-823.

2. Ford ML, Tomlinson LA, Chapman TP, Rajkumar C, Holt SG: Aortic stiffness is independently associated with rate of renal function decline in chronic kidney disease stages 3 and 4. Hypertension 2010, 55(5):1110-1115.

3. Henle T, Miyata T: Advanced glycation end products in uremia. Adv Ren Replace Ther 2003, 10(4):321-331.
4. Meerwaldt R, Zeebregts CJ, Navis G, Hillebrands JL, Lefrandt JD, Smit AJ: Accumulation of advanced glycation end products and chronic complications in ESRD treated by dialysis. Am J Kidney Dis 2009, 53(1):138-150.

5. Sajithlal GB, Chithra P, Chandrakasan G: Advanced glycation end products induce crosslinking of collagen in vitro. Biochim Biophys Acta 1998, 1407(3):215-224

6. Cooper ME: Importance of advanced glycation end products in diabetesassociated cardiovascular and renal disease. Am J Hypertens 2004, 17(12 Pt 2):31S-38S

7. Wendt TM, Tanji N, Guo J, Kislinger TR, Qu W, Lu Y, Bucciarelli LG, Rong LL, Moser B, Markowitz GS, et al: RAGE drives the development of glomerulosclerosis and implicates podocyte activation in the pathogenesis of diabetic nephropathy. Am J Pathol 2003, 162(4):1123-1137.

8. Gu L, Hagiwara S, Fan Q, Tanimoto M, Kobata M, Yamashita M, Nishitani T, Gohda T, Ni Z, Qian J, et al: Role of receptor for advanced glycation endproducts and signalling events in advanced glycation end-productinduced monocyte chemoattractant protein-1 expression in differentiated mouse podocytes. Nephrol Dial Transplant 2006, 21(2):299-313.

9. Yue WS, Lau KK, Siu CW, Wang M, Yan GH, Yiu KH, Tse HF: Impact of glycemic control on circulating endothelial progenitor cells and arterial stiffness in patients with type 2 diabetes mellitus. Cardiovasc Diabetol 2011, 10:113.

10. Lijnen PJ, Petrov W, Fagard RH: Angiotensin II-induced stimulation of collagen secretion and production in cardiac fibroblasts is mediated via angiotensin II subtype 1 receptors. Journal of the Renin-AngiotensinAldosterone system: JRAAS 2001, 2(2):117-122.

11. Miyata $T$, van Ypersele de Strihou C, Ueda $Y$, Ichimori $K$, Inagi $R$, Onogi $H$, Ishikawa N, Nangaku M, Kurokawa K: Angiotensin II receptor antagonists and angiotensin-converting enzyme inhibitors lower in vitro the formation of advanced glycation end products: biochemical mechanisms. Journal of the American Society of Nephrology: JASN 2002, 13(10):2478-2487.

12. Vaziri ND, Bai Y, Ni Z, Quiroz Y, Pandian R, Rodriguez-Iturbe B: Intra-renal angiotensin II/AT1 receptor, oxidative stress, inflammation, and progressive injury in renal mass reduction. J Pharmacol Exp Ther 2007, 323(1):85-93.

13. Mogensen CE, Neldam S, Tikkanen I, Oren S, Viskoper R, Watts RW, Cooper ME: Randomised controlled trial of dual blockade of renin-angiotensin system in patients with hypertension, microalbuminuria, and non-insulin dependent diabetes: the candesartan and lisinopril microalbuminuria (CALM) study. BMJ 2000, 321(7274):1440-1444.

14. Parving HH, Persson F, Lewis JB, Lewis EJ, Hollenberg NK: Aliskiren combined with losartan in type 2 diabetes and nephropathy. $N$ Engl $J$ Med 2008, 358(23):2433-2446.

15. Busch M, Franke S, Wolf G, Rohde RD, Stein G: Serum levels of the advanced glycation end products Nepsilon-carboxymethyllysine and pentosidine are not influenced by treatment with the angiotensin receptor II type 1 blocker irbesartan in patients with type 2 diabetic nephropathy and hypertension. Nephron Clin Pract 2008, 108(4):c291-c297.

16. Fliser D, Wagner KK, Loos A, Tsikas D, Haller H: Chronic angiotensin II receptor blockade reduces (intra)renal vascular resistance in patients with type 2 diabetes. Journal of the American Society of Nephrology: JASN 2005, 16(4):1135-1140.

17. Kadowaki D, Anraku M, Tasaki Y, Taguchi K, Shimoishi K, Seo H, Hirata S, Maruyama T, Otagiri M: Evaluation for antioxidant and renoprotective activity of olmesartan using nephrectomy rats. Biol Pharm Bull 2009, 32(12):2041-2045.

18. Navar LG: The role of the kidneys in hypertension. J Clin Hypertens (Greenwich) 2005, 7(9):542-549.

19. Paul M, Poyan Mehr A, Kreutz R: Physiology of local renin-angiotensin systems. Physiol Rev 2006, 86(3):747-803.

20. Haller H, Ito S, Izzo JL Jr, Januszewicz A, Katayama S, Menne J, Mimran A Rabelink TJ, Ritz E, Ruilope LM, et al: Olmesartan for the delay or prevention of microalbuminuria in type 2 diabetes. N Engl J Med 2011, 364(10):907-917.

21. Lin SL, Chen YM, Chien CT, Chiang WC, Tsai CC, Tsai TJ: Pentoxifylline attenuated the renal disease progression in rats with remnant kidney. Journal of the American Society of Nephrology: JASN 2002, 13(12):2916-2929. 
22. Chang KC, Hsu KL, Tseng YZ: Effects of diabetes and gender on mechanical properties of the arterial system in rats: aortic impedance analysis. Exp Biol Med (Maywood) 2003, 228(1):70-78

23. Mitchell GF, Pfeffer MA, Westerhof N, Pfeffer JM: Measurement of aortic input impedance in rats. Am J Physiol 1994, 267(5 Pt 2):H1907-H1915.

24. Milnor WR: Hemodynamics. Baltimore: Williams \& Wilkins Co; 1989.

25. Nichols WW, O'Rourke MF: McDonald's Blood Flow in Arteries. London: Arnold; 1998.

26. Gaballa MA, Raya TE, Hoover CA, Goldman S: Effects of endothelial and inducible nitric oxide synthases inhibition on circulatory function in rats after myocardial infarction. Cardiovasc Res 1999, 42(3):627-635.

27. Huijberts MS, Wolffenbuttel BH, Boudier HA, Crijns FR, Kruseman AC, Poitevin P, Levy BI: Aminoguanidine treatment increases elasticity and decreases fluid filtration of large arteries from diabetic rats. J Clin Invest 1993, 92(3):1407-1411.

28. Liu Z, Brin KP, Yin FC: Estimation of total arterial compliance: an improved method and evaluation of current methods. Am J Physiol 1986, 251(3 Pt 2):H588-H600.

29. Laxminarayan S, Sipkema P, Westerhof N: Characterization of the arterial system in the time domain. IEEE Trans Biomed Eng 1978, 25(2):177-184.

30. Westerhof N, Sipkema P, van den Bos GC, Elzinga G: Forward and backward waves in the arterial system. Cardiovasc Res 1972, 6(6):648-656

31. Turk Z, Misur I, Turk N, Benko B: Rat tissue collagen modified by advanced glycation: correlation with duration of diabetes and glycemic control. Clin Chem Lab Med 1999, 37(8):813-820.

32. Lapolla A, Brancia FL, Bereszczak J, Fedele D, Baccarin L, Seraglia R, Traldi P: Off-line liquid chromatography-MALDI by with various matrices and tandem mass spectrometry for analysis of glycated human serum albumin tryptic peptides. Mol Nutr Food Res 2007, 51(4):456-461.

33. Stumpe KO, Agabiti-Rosei E, Zielinski T, Schremmer D, Scholze J, Laeis P, Schwandt $\mathrm{P}$, Ludwig M: Carotid intima-media thickness and plaque volume changes following 2-year angiotensin II-receptor blockade. The Multicentre Olmesartan atherosclerosis Regression Evaluation (MORE) study. Ther Adv Cardiovasc Dis 2007, 1(2):97-106.

34. Nishida Y, Takahashi Y, Nakayama T, Soma M, Asai S: Comparative effect of olmesartan and candesartan on lipid metabolism and renal function in patients with hypertension: a retrospective observational study. Cardiovasc Diabetol 2011, 10:74.

35. Ono M, Fukuda M, Miura T, Mizuno M, Kato Y, Sato R, Naito T, Togawa H, Sasakawa $Y$, Tomonari $T$, et al: Predictors of proteinuria reduction by monotherapy with an angiotensin receptor blocker, olmesartan. Journal of the renin-angiotensin-aldosterone system: JRAAS 2012, 13(2):239-243.

36. Zhang H, Ma G, Yao Y, Qian H, Li W, Chen X, Jiang W, Zheng R: Olmesartan Attenuates the Impairment of Endothelial Cells Induced by Oxidized Low Density Lipoprotein through Downregulating Expression of LOX-1. Int J Mol Sci 2012, 13(2):1512-1523.

37. Brousil JA, Burke JM: Olmesartan medoxomil: an angiotensin II-receptor blocker. Clin Ther 2003, 25(4):1041-1055.

38. Vaziri ND, Dicus M, Ho ND, Boroujerdi-Rad L, Sindhu RK: Oxidative stress and dysregulation of superoxide dismutase and NADPH oxidase in renal insufficiency. Kidney Int 2003, 63(1):179-185.

39. Fujimoto $S$, Satoh M, Horike H, Hatta H, Haruna Y, Kobayashi S, Namikoshi T, Arakawa S, Tomita N, Kashihara N: Olmesartan ameliorates progressive glomerular injury in subtotal nephrectomized rats through suppression of superoxide production. Hypertens Res 2008, 31(2):305-313.

40. Chang KC, Tseng CD, Wu MS, Liang JT, Tsai MS, Cho YL, Tseng YZ: Aminoguanidine prevents arterial stiffening in a new rat model of type 2 diabetes. Eur J Clin Invest 2006, 36(8):528-535.

41. Aronson D: Cross-linking of glycated collagen in the pathogenesis of arterial and myocardial stiffening of aging and diabetes. J Hypertens 2003, 21(1):3-12.

42. Bohlender J, Franke S, Sommer M, Stein G: Advanced glycation end products: a possible link to angiotensin in an animal model. Ann N Y Acad Sci 2005, 1043:681-684.

43. Meerwaldt R, Links T, Zeebregts C, Tio R, Hillebrands JL, Smit A: The clinical relevance of assessing advanced glycation endproducts accumulation in diabetes. Cardiovasc Diabetol 2008, 7:29.

44. Lapolla A, Piarulli F, Sartore G, Ceriello A, Ragazzi E, Reitano R, Baccarin L, Laverda B, Fedele D: Advanced glycation end products and antioxidant status in type 2 diabetic patients with and without peripheral artery disease. Diabetes Care 2007, 30(3):670-676.
45. Kuo HT, Kuo MC, Chiu YW, Chang JM, Guh JY, Chen HC: Increased glomerular and extracellular malondialdehyde levels in patients and rats with focal segmental glomerulosclerosis. Eur J Clin Invest 2005, 35(4):245-250

46. Schleicher E, Friess U: Oxidative stress, AGE, and atherosclerosis. Kidney Int Supp/ 2007, 106:S17-S26.

47. Miyata T, van Ypersele de Strihou C: Angiotensin II receptor blockers and angiotensin converting enzyme inhibitors: implication of radical scavenging and transition metal chelation in inhibition of advanced glycation end product formation. Arch Biochem Biophys 2003, 419(1):50-54.

48. Bohlender JM, Franke S, Stein G, Wolf G: Advanced glycation end products and the kidney. Am J Physiol Renal Physiol 2005, 289(4):F645-F659.

49. Thornalley PJ: Glycation free adduct accumulation in renal disease: the new AGE. Pediatr Nephrol 2005, 20(11):1515-1522.

50. Izuhara $Y$, Nangaku M, Inagi R, Tominaga N, Aizawa T, Kurokawa K, van Ypersele de Strihou C, Miyata T: Renoprotective properties of angiotensin receptor blockers beyond blood pressure lowering. J Am Soc Nephrol 2005, 16(12):3631-3641.

doi:10.1186/1475-2840-11-66

Cite this article as: Chuang et al.: Effects of olmesartan on arterial stiffness in rats with chronic renal failure. Cardiovascular Diabetology 2012 11:66.

\section{Submit your next manuscript to BioMed Central and take full advantage of:}

- Convenient online submission

- Thorough peer review

- No space constraints or color figure charges

- Immediate publication on acceptance

- Inclusion in PubMed, CAS, Scopus and Google Scholar

- Research which is freely available for redistribution

Submit your manuscript at www.biomedcentral.com/submit
C) Biomed Central 